\title{
Electronic journals are already here
}

This year's gathering of publishers at Frankfurt has made it plain that the electronic distribution of research data is no longer in the future, but in the here and now.

Frankfurt. After several years in which publishers have been proclaiming that electronic publishing is around the corner, many now seem willing to acknowledge that it has arrived. Indeed, at this year's Book Fair, a whole exhibition has been given over to electronic publishing in various forms. Some commercial publishers are plainly prepared to get their feet wet, and to risk their capital as well, in this brave new world. But, wisely, nobody is pretending that what is now on show is what the book fair will be like a decade or so from now.

Indeed, by the standards of the research community's use of Internet and the other readily accessible electronic networks, the ventures of general publishers into the electronic future are elementary at least. What has happened is merely that several publishers have recognized the convenience of compact discs as a means of distributing data for which there is a general market, dictionaries and other reference works for example. For the time being at least, there are not many competing formats to confuse the customer (and complicate the manufacturing process). With bit-mapped images, the capital cost of piracy is high, comparable with the cost of pirating a printed book. And selling large numbers of identical compact discs is not very different from selling books. It is easy to feel technically advanced when nothing much has changed.

Whether the few signs at this year's fair of a more complicated time ahead are to be taken seriously is far from clear. Some general publishers have been captivated by the multimedia craze, offering compact discs carrying both text and illustrations. The snags, for the time being, are that the quality of the illustrations is not high and their interleaving with the text is artificial, much as if a book illustrator had been commissioned to produce 'something' every eight pages or so. But that could change. So could the sophistication of educational packages intended both as textbooks and compilations of relevant data. That is where the general publishers are likely first to strike electronic gold.

The future of scientific publishing is altogether a different question, if only because of the access to digital electronic networks which the research community has enjoyed for many years, and which it now relies upon. Although compact discs are sometimes used (especially, for example, for the transfer of large amounts of numerical data in digital form), they already have an old-fashioned air. Who wants to be hunting for physical discs in a small filing cabinet when it should be possible to retrieve the same data directly onto a screen simply by typing a remembered filename?

Whence the general sense that scientific journals (and their publishers) are heading for a revolution. This year's symposium of the STM (for "science, technology and medicine") publishers' group, ostensibly about the "information explosion" in the field of scholarship as a whole, could not keep off the question whether true electronic networking of scientific texts will blunt whatever difficulties there may be in keeping up with the literature. One participant claimed that there are already 130 strictly electronic journals, but there is no listing of them.

The plain truth of course, is that the publication of research material by means of electronic networks is inevitable. Indeed, in some fields, it is already standard practice. In both particle physics and astronomy, it has become standard practice for people to list the titles of their latest preprints on bulletin boards, from which copies can be retrieved electronically.

Opinions of this informal service vary. Some say that they now use the journals in their field only to look up articles published before the coming of the networks, others that they prefer to judge for themselves whether a paper makes sense and do not set much store by its validation by referees before its publication as ink on paper - and still others that the information explosion is an illusion, given that they learn all they need to know from their graduate students and on the telephone - the 'personal communication' of the formal paper.

These developments raise awkward problems, both for the research community and for publishers. There is every likelihood that it is a matter of a few years only before the practice long-established in particle physics has spread to many other fields. (The frequency with which biologists now sport Internet addresses is already conspicuous.) But the question will then arise of whether the formal publication of research articles in what are at present called journals will continue to make sense.

Even in particle physics, there are many who still hold that formal publication will always be necessary. For how else are future cohorts of researchers to be guided towards the literature worth taking seriously? Certainly those who make appointments and promotions, and who award research grants, continue to set great store by publication in journals that have been rigorously refereed.
But will referees continue to perform their invaluable unpaid services with a good grace, or at all, if they know that they are commenting on research articles that have already been distributed to all those likely to be interested, and which are unlikely to be read a second time even if they are substantially changed after being refereed? That seems improbable. In short, when access to the networks is universal, it seems unlikely that the concept of the journal as an authenticating agent will survive even in an electronic form.

In the circumstances, it is perhaps as well that there remain a few obstacles to this free flow of data and its interpretation. Thus photographs used as illustrations remain a technical problem; although compression by a factor of about 50 is possible, making handling more economical, there is still no uniformly agreed format by which that can be done. But that can be only a passing difficulty.

More seriously, there is the threat that access to the networks will not indefinitely be free of charge, and that charges may be levied that are somehow related to the use made of them. Not only the Russian scientists who have learned to live by the networks would find such a development devastating. Yet it is a curious feature of present arrangements that the research community prefers that this crucial issue should not be discussed. It is as if people believe that network charges are not yet a reality because the issue has been overlooked.

The publishers' dilemma (which in this context includes the learned society publishers of important journais, many of whom derive the bulk of their income from this source) is different and old-fashioned. Who will continue to buy ink-on-paper journals when most of the contents, admittedly in unrefereed form, have already been distributed on the networks? Seeking to outwit events by publishing journals electronically is no defence, because there is no obvious way of restricting unlicensed copying. Either way, there is a prospect of continuing overhead costs and shrinking revenue.

Luckily, again, the revolution will not happen tomorrow, or even the day after. There will be some time to adjust. But it is interesting, to judge from the Frankfurt meeting, that publishers are only now facing up to what may lie ahead. It is as if they have believed that, by saying nothing, they could avoid inviting trouble. Is it possible that, by next year, they will even be talking to the scientific community?

John Maddox 